\title{
Article \\ Biplane Trajectory Tracking Using Hybrid Controller Based on Backstepping and Integral Terminal Sliding Mode Control
}

\author{
Nihal Dalwadi ${ }^{1,+}$, Dipankar Deb ${ }^{1, *,+(\mathbb{C}}$ and Jagat Jyoti Rath ${ }^{2,+}$ \\ 1 Department of Electrical Engineering, Institute of Infrastructure Technology Research and Management \\ (IITRAM), Ahmedabad 380026, India; nihal.dalwadi.20pe@iitram.ac.in \\ 2 Department of Mechanical and Aerospace Engineering, Institute of Infrastructure Technology Research and \\ Management (IITRAM), Ahmedabad 380026, India; jagat.rath@iitram.ac.in \\ * Correspondence: dipankardeb@iitram.ac.in \\ + These authors contributed equally to this work.
}

check for

updates

Citation: Dalwadi, N.; Deb, D.; Rath, J.J. Biplane Trajectory Tracking Using Hybrid Controller Based on Backstepping and Integral Terminal Sliding Mode Control. Drones 2022, 6, 58. https://doi.org/10.3390/ drones6030058

Academic Editors: Mehdi Ghommem, Jawher Ghommam, Brahim Brahmi and Quanmin Zhu

Received: 30 December 2021 Accepted: 14 February 2022 Published: 24 February 2022

Publisher's Note: MDPI stays neutral with regard to jurisdictional claims in published maps and institutional affiliations.

Copyright: (C) 2022 by the authors. Licensee MDPI, Basel, Switzerland. This article is an open access article distributed under the terms and conditions of the Creative Commons Attribution (CC BY) license (https:// creativecommons.org/licenses/by/ $4.0 /)$.

\begin{abstract}
A biplane quadrotor is a hybrid type of Unmanned Aerial Vehicle (UAV) that has advantages of both fixed-wing and rotary-wing UAVs. In this study, we design controllers using (i) Backstepping Control (BSC), (ii) Integral Terminal Sliding Mode Control (ITSMC), and (iii) Hybrid control (ITSMC + BSC), where the ITSMC controls attitude and BSC controls the altitude subsystems as per the mathematical model of biplane quadrotor. The performance of these controllers is evaluated based on the autonomous trajectory tracking containing all possible maneuvers and operation modes that the biplane quadrotor can perform. Performance analysis reveals that the BSC-based controller is susceptible to a steady-state error in altitude tracking when mass is changed. In contrast, the ITSMC and the "hybrid" controllers achieve smooth tracking in a finite time. Furthermore, the "hybrid" controller outperforms the other designs, reducing tracking error and faster convergence time.
\end{abstract}

Keywords: biplane quadrotor; integral terminal sliding mode controller; backstepping control; hybrid controller; trajectory tracking

\section{Introduction}

UAVs have significantly evolved in miniaturization, modeling, control, prototyping, and energy-efficient hybrid configurations [1-3]. For example, a simple tail-sitter structure avoids a mechanically complex design involving multiple moving parts. Still, the whole body tilts as the vehicle transitions from quadrotor mode to forward flight. A biplane quadrotor, an under-actuated and hybrid tail-sitter, combines the advantages of both rotary-wing and fixed-wing UAVs. For biplane quadrotors, research has focused on the development of control strategies for different flight regimes [4,5], mission planning strategies [6], modeling and trajectory planning [7], and improved performance under wind gust disturbances [8], along with some real-time implementation of control strategies [9]. As the biplane involves both quadrotor and level flight modes, advanced strategies explore the handling of the transition between these modes [7,9]. Furthermore, ref. [10] proposes a biplane quadrotor design with variable pitch propellers for a package delivery mission, highlighting the applicability of such designs for real-world problems.

As the design of control strategies to handle both flight modes of a biplane is very significant, several techniques inclusive of Proportional-Integral-Derivative (PID) [11], Linear Quadratic Regulator (LQR) [12], adaptive and nonlinear control [13-15], sliding mode control [16-18], back-stepping control [19], and $H_{\infty}$ control [20] have been proposed. Trajectory tracking under different scenarios is observed [11,12] by using PID and LQR techniques. Nonlinear PID (NPID) for the quadrotor UAV is proposed in [21], while a Novel PID-type motion controller is implemented in [22]. A variable universe fractal dual fuzzy PID controller is proposed in [23] for the tail-sitter UAV to handle the variations in airspeed and aerodynamic structures during the transition mode. PID controllers with 
gain scheduling for a tail-sitter UAV [24] provide improved performance. A camera-based positioning system for quadcopters has been presented for the automatic landing with PID Control for the attitude and PD controller for the position [25]. Intelligent flight PID, LQR, and State feedback controllers are implemented in the nonlinear model of X3D Quadrotor [26].

Furthermore, by the use of optimization approaches, such as intelligent particle swarm optimization $[27,28]$, the performance of gain scheduled PID controllers are also enhanced. Improving upon such architectures, in [14], a robust nonlinear trajectory tracking control during flight mode transitions without switching the coordinates was proposed. Along similar lines, a sliding mode controller for a fixed-wing UAV to keep tracking an awkward, moving target and also maintain a continuous circular motion concerning the moving target is proposed in [17]. Along with trajectory tracking, robustness to crosswinds and other external disturbances is a significant problem for biplane quadrotor configurations. The main disadvantages of such control algorithms are their lack of robustness, their limited range of operation, and their requirement for detailed dynamics of the UAV.

Addressing robustness to crosswinds, nonlinear disturbance observers were designed $[19,20]$. Such observers achieve robust trajectory tracking with backstepping controllers and $H_{\infty}$ techniques. For improved convergence time along with disturbance rejection, a hybrid PD-adaptive neuro-fuzzy controller is proposed [29]. Similarly, proportional derivative and adaptive integral backstepping control techniques [30] are used together to control the position within a building-generated wind wake disturbance. Backstepping controllers and adaptive backstepping controllers are proposed for the trajectory tracking and payload delivery by using biplane quadrotors [31]. The backstepping control method requires full-state measurement and a large magnitude of control signals, while the neuro-fuzzy controller has a lack of robustness and required expertise for a good initialization.

An animated picture of the biplane quadrotor is shown in Figure 1. During take-off, landing, and hovering, biplane quadrotors act as conventional rotary wing UAVs, and after performing the transition maneuver, they fly with high velocity as a fixed-wing UAV.

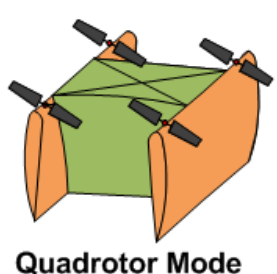

$\uparrow$

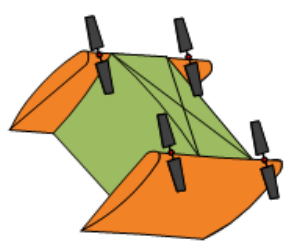

Transition Mode

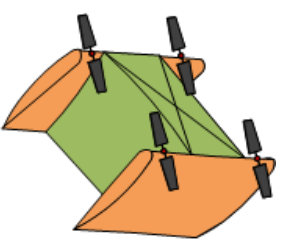

Transition mode

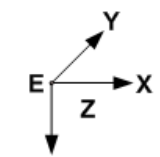

Inertial Frame

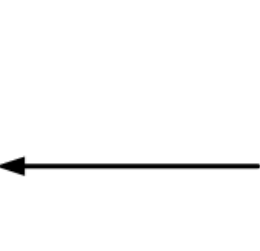

Fixed wing Mode

Figure 1. Animated picture of biplane quadrotor.

The ability to reject disturbances along with finite time convergent properties $[32,33]$ of the integral terminal sliding mode control (ITSMC) strategies have led to their significant use in various UAV works [34-36]. A complete flight trajectory tracking control law for quadcopter UAVs operated under matched uncertainties is proposed [34]. Similarly, in [35], a robust ITSMC controller for the attitude control along with an adaptive backstepping for 
position and altitude was developed. For improving the rate of convergence and accuracy, adaptive fractional-order non-singular fast terminal sliding mode controllers in the presence of random external disturbances and parametric uncertainties for UAVs are proposed [36]. Integrating SMC techniques with PID, a two-part control scheme for a 6-DOF UAV system affected with external disturbance due to sensor failure is proposed [37]. Similarly, the attitude controller uses an integrated design of integral backstepping control (IBS) and an adaptive terminal sliding mode control (ATSMC) for a quadrotor [38]. Addressing the issues of disturbance rejection along with actuator faults, an adaptive backstepping sliding mode controller with the swapping gain generated by a backstepping controller was proposed in [39] for a quadrotor.

Researchers have developed algorithms for trajectory tracking of rotary-wing UAVs, fixed-wing UAVs, and hybrid UAVs such as a quadrotor tail-sitter, quadrotor tail-rotor, etc. In this work, we design BSC, ITSMC, and a Hybrid controller (ITSMC + BSC), which is more robust, provides a faster response, and comes in a simple structure, for a biplane quadrotor to track the autonomous trajectory containing all the modes to ensure appropriate maneuvers. Furthermore, controller performance is evaluated based on the trajectory tracking in different modes and scenarios and during mass change. The rest of the paper is as follows: Section 2 presents the biplane quadrotor dynamics. Section 3 designs the ITSMC and backstepping controller for the quadrotor, transition mode, and fixed-wing mode. Section 4 presents the results and discussions of the simulation study to demonstrate controller performance, followed by concluding remarks in Section 5.

\section{Mathematical Model of Biplane Quadrotor}

The biplane quadrotor's 6-degrees-of-freedom (DOF) dynamics [4] are:

$$
\begin{aligned}
& {\left[\begin{array}{c}
\ddot{x} \\
\ddot{y} \\
\ddot{z}
\end{array}\right]=\frac{1}{m}\left[\begin{array}{c}
F_{a x} \\
F_{a y} \\
-T+F_{a z}
\end{array}\right]+g\left[\begin{array}{c}
-s \theta \\
c \theta s \phi \\
c \theta c \phi
\end{array}\right]\left[\begin{array}{l}
r v-q w \\
p w-r u \\
q u-p v
\end{array}\right],} \\
& {\left[\begin{array}{c}
\ddot{\phi} \\
\ddot{\theta} \\
\ddot{\psi}
\end{array}\right]=\left[\begin{array}{c}
\left(b_{1} r+b_{2} p\right) q+b_{3}\left(L_{a}+L_{t}\right)+b_{4}\left(N_{a}+N_{t}\right) \\
b_{5} p r-b_{6}\left(p^{2}-r^{2}\right)+b_{7}\left(M_{a}+M_{t}\right) \\
\left(b_{8} p-b_{2} r\right) q+b_{4}\left(L_{a}+L_{t}\right)+b_{9}\left(N_{a}+N_{t}\right)
\end{array}\right] .}
\end{aligned}
$$

where $c(\cdot)=\cos (\cdot)$ and $s(\cdot)=\sin (\cdot),[\ddot{x} \ddot{y} \ddot{z}]$ and $[\ddot{\phi} \ddot{\theta} \ddot{\psi}]$ are the linear and angular accelerations, and $[p q r]$ and $[u v w]$ are the angular and linear velocities. $m$ is the mass and $T$ is the thrust, $\left[L_{t} M_{t} N_{t}\right]$ are the moments of the roll, pitch, and yaw angles; $\left[F_{a x} F_{a y} F_{a z}\right]$ and $\left[L_{a} M_{a} N_{a}\right]$ are the aerodynamic forces and the aerodynamic moments acting on the biplane quadrotor, respectively. Inertial terms are defined as constant $b_{i}$ :

$$
\left[\begin{array}{l}
b_{1} \\
b_{2} \\
b_{3} \\
b_{4} \\
b_{8} \\
b_{9}
\end{array}\right]=\frac{1}{I_{x} I_{z}-I_{x z}^{2}}\left[\begin{array}{c}
\left(I_{y}-I_{z}\right) I_{z}-I_{x z}^{2} \\
\left(I_{x}-I_{y}+I_{z}\right) I_{x z} \\
I_{z} \\
I_{x z} \\
\left(I_{x}-I_{y}\right) I_{x}+I_{x z}^{2} \\
I_{x}
\end{array}\right],\left[\begin{array}{l}
b_{5} \\
b_{6} \\
b_{7}
\end{array}\right]=\frac{1}{I_{y}}\left[\begin{array}{c}
\left(I_{z}-I_{x}\right) \\
I_{x z} \\
1
\end{array}\right] .
$$

The aerodynamic forces in the quadrotor frame and the moments due to aerodynamic forces are defined as:

$$
\left[\begin{array}{c}
F_{a x} \\
F_{a y} \\
F_{a z}
\end{array}\right]=\left[\begin{array}{ccc}
s \alpha c \alpha & -s \alpha s \beta & c \alpha \\
s \beta & c \beta & 0 \\
-c \alpha c \beta & c \alpha s \beta & s \alpha
\end{array}\right]\left[\begin{array}{c}
-D \\
Y \\
-L
\end{array}\right]\left[\begin{array}{c}
L_{a} \\
M_{a} \\
N_{a}
\end{array}\right]=\left[\begin{array}{c}
0.5 \rho V^{2} S b C_{l} \\
0.5 \rho \bar{c} V^{2} S C_{m} \\
0.5 \rho V^{2} S b C_{n}
\end{array}\right],
$$

where $C_{l}, C_{m}$, and $C_{n}$ are the non-dimensional coefficients of the total rolling, pitching, and yawing moments due to aerodynamic forces [4]. The velocity of the biplane quadrotor is $V=\sqrt{u^{2}+v^{2}+w^{2}}$. 


\section{Hybrid Controller Design}

Next, we design a hybrid controller in which the BSC and ITSMC control the attitude and position subsystems, respectively, for autonomous trajectory tracking. We consider all modes and phases such as take-off, hovering, transition, level flight, and landing.

\subsection{Quadrotor Mode}

In the quadrotor mode, the aerodynamic forces and moments acting on the biplane quadrotor are neglected since the angular velocity is almost zero during the take-off, hovering, and landing phases. The thrust generated by the motors balances the weight of the biplane quadrotor. For the quadrotor mode, the dynamics using (1) and (2) are:

$$
\begin{aligned}
& m\left[\begin{array}{lll}
\ddot{x} & \ddot{y} & \ddot{z}
\end{array}\right]^{T}=\left[\begin{array}{lll}
0 & 0 & m g
\end{array}\right]^{T}+R_{T}\left[\begin{array}{lll}
0 & 0 & -T
\end{array}\right]^{T} \\
& {\left[\begin{array}{c}
\ddot{\phi} \\
\ddot{\theta} \\
\ddot{\psi}
\end{array}\right]=\left[\begin{array}{c}
\left(b_{1} r+b_{2} p\right) q+b_{3}\left(L_{a}+L_{t}\right)+b_{4}\left(N_{a}+N_{t}\right) \\
b_{5} p r-b_{6}\left(p^{2}-r^{2}\right)+b_{7}\left(M_{a}+M_{t}\right) \\
\left(b_{8} p-b_{2} r\right) q+b_{4}\left(L_{a}+L_{t}\right)+b_{9}\left(N_{a}+N_{t}\right)
\end{array}\right]} \\
& R_{T}=\left[\begin{array}{ccc}
c \phi c \psi & s \phi s \theta c \psi-c \phi s \psi & c \phi s \theta c \psi+s \phi s \psi \\
c \theta s \psi & s \phi s \theta s \psi+c \phi c \psi & c \phi s \theta s \psi-s \phi c \psi \\
-s \theta & s \phi c \theta & c \phi c \theta
\end{array}\right] .
\end{aligned}
$$

Using (5) and (6), the control law for the position and attitude subsystems are designed. The controller design based on Figure 2 is possible in the following ways:

- $\quad$ For the BSC-based control, controller 1 (Position controller) and controller 2 (Attitude controller) blocks are both backstepping controllers.

- $\quad$ For ITSMC based control, controller 1 and controller 2 are both replaced by ITSMCs.

- For the Hybrid controller, controller 1 is replaced by an ITSMC and controller 2 is replaced by a BSC.

- In hybrid control, controller 1 can be replaced by the BSC and controller 2 can be replaced by the ITSMC, but in this simulation study, we consider only the above case for the hybrid controller. More details are in the Results and Discussions section.

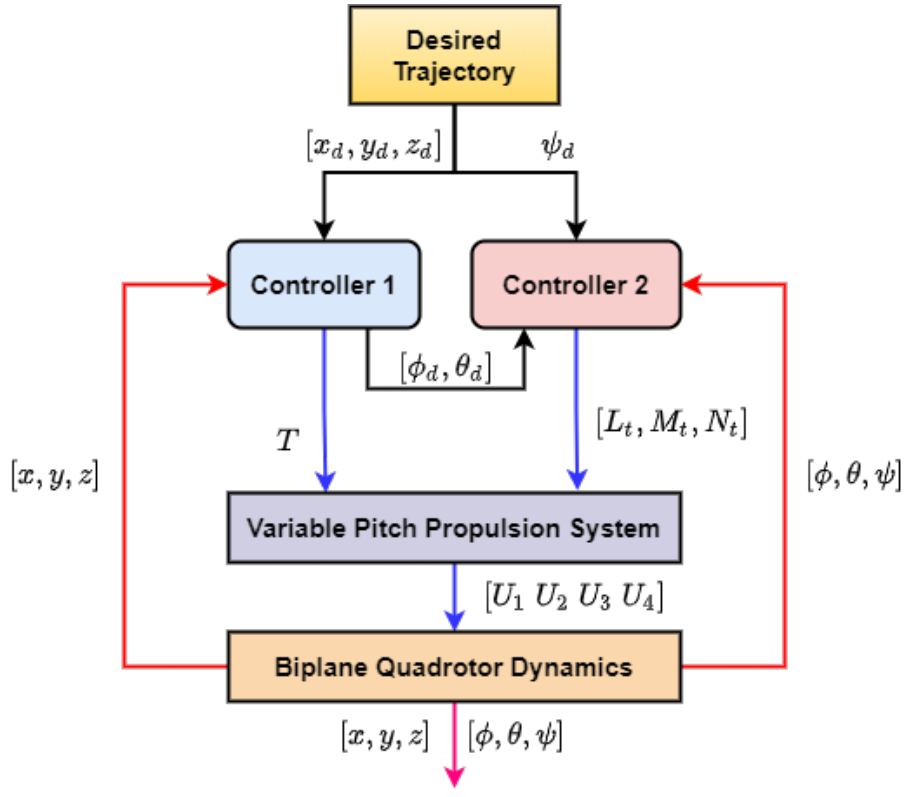

Figure 2. Block Diagram of controller design.

The position controller calculates the desired thrust $(T)$ based on the desired signal. For the attitude controller, the desired roll and pitch angle is calculated using $\left[x_{d} y_{d}\right]$ and the desired yaw angle $\left(\psi_{d}\right)$ is directly given. Based on these signals, the desired roll, pitch, 
and yaw moments $\left[L_{t} M_{t} N_{t}\right]$ are generated and given to the propulsion system, and then the desired signal for the motors $\left[U_{1} U_{2} U_{3} U_{4}\right]$ are generated.

In the next section, the hybrid controller design and stability analysis is shown. As explained earlier, the attitude of the biplane quadrotor is controlled by the BSC controller, while the ITSMC-based controller controls position and altitude.

\subsubsection{ITSMC Design}

To design an ITSMC-based controller for the position and altitude control of the biplane quadrotor, we first define the sliding surface [35] as:

$$
S=\dot{e}+\int \gamma \dot{e}^{j / i}+\zeta e^{\frac{j}{2 i-1}}
$$

and the reaching law is selected as:

$$
\dot{S}=-\lambda S-k \operatorname{sign}(S)
$$

where $0<j / i<1, \gamma, \zeta, k, \lambda>0$. Now, the error between the actual altitude and desired altitude is given by $e_{z_{q}}=z-z_{d}$. Here, suffix $q$ is for the quadrotor mode and transition mode. A positive definite function is defined as $V_{z_{q}}=\frac{1}{2} S_{z_{q}}^{2}$. By taking its time derivative and using (5), we obtain:

$$
\begin{aligned}
\dot{V}_{z_{q}} & =S_{z_{q}}\left(\ddot{z}-\ddot{z}_{d}+\gamma_{z_{q}} \dot{e}^{j_{z_{q}} / i_{z_{q}}}+\zeta_{z_{q}} e^{\frac{j_{z q}}{2 i_{z_{q}}-1}}\right) \\
& =S_{z_{q}}\left(g-\frac{T}{m} c \phi c \theta-\ddot{z}_{q_{d}}+\gamma_{z_{q}} \dot{e}^{j_{z_{q}} / i_{z_{q}}}+\zeta_{z_{q}} e^{\frac{j_{z_{q}}-1}{i_{z_{q}}}}\right) .
\end{aligned}
$$

Using (9), the control law is defined as:

$$
T=\frac{m}{c \phi c \theta}\left(g-\ddot{z}_{d}+\gamma_{z_{q}} e_{z_{q}}^{j_{z q} / i_{z_{q}}}+\zeta_{z_{q}}^{\frac{j i_{z_{q}}+j_{z_{q}}}{2}}+\lambda_{z_{q}} S_{z_{q}}+k_{z_{q}} \operatorname{sign}\left(S_{z_{q}}\right)\right)
$$

such that $\dot{V}_{z_{q}}=-\lambda_{z_{q}} S_{z_{q}}^{2}-k_{z_{q}}\left|S_{z_{q}}\right| \leq 0$, where $\lambda_{z_{q}}, k_{z_{q}}>0$. Control laws for the $x-y$ position are defined using the same procedure:

$$
\begin{aligned}
& U_{x}=\frac{m}{T}\left(-\ddot{x}_{d}+\gamma_{x_{q}} \dot{e}_{x_{q}}^{j_{x_{q}} / i_{x_{q}}}+\zeta_{x_{q}}^{\frac{j x_{x_{q}}-j x_{q}}{2}}+\lambda_{x_{q}} S_{x_{q}}+k_{x_{q}} \operatorname{sign}\left(S_{x_{q}}\right)\right), \lambda_{x_{q}}, k_{x_{q}}>0, \\
& U_{y}=\frac{m}{T}\left(-\ddot{y}_{d}+\gamma_{y_{q}} \dot{e}_{y_{q}}^{j_{y_{q}} / i_{y_{q}}}+\zeta_{y_{q}}^{\frac{j_{y_{q}}-j_{y_{q}}}{i_{y_{q}}}}+\lambda_{y_{q}} S_{y_{q}}+k_{y_{q}} \operatorname{sign}\left(S_{y_{q}}\right)\right), \lambda_{y_{q}}, k_{y_{q}}>0 .
\end{aligned}
$$

Using (11) and (12), the desired roll and pitch angles are designed as:

$$
\phi_{d}=\sin ^{-1}\left(s \psi_{d} U_{y}+c \psi_{d} U_{x}\right), \quad \theta_{d}=\sin ^{-1}\left(\left(c \psi_{d} U_{x}+s \psi_{d} U_{y}\right) c \phi_{d}\right),
$$

where $-\frac{\pi}{2}<\phi_{d}<\frac{\pi}{2},-\frac{\pi}{2}<\theta_{d}<\frac{\pi}{2}$ and $-\pi<\psi_{d}<\pi$ are reasonable bounds that avoid singularity in (10). The position subsystem is controlled by (10)-(12), and based on these, the desired roll and pitch angles are given in (13). These desired angles are the inputs of the attitude controller designed based on the BSC described next.

\subsubsection{BSC Design}

The attitude of the biplane quadrotor is controlled by the BSC controller. Som the error between the actual roll angle and the desired roll angle is given by $e_{\phi_{q}}=\phi-\phi_{d}$. A positive definite function is defined as $V_{\phi_{q}}=\frac{1}{2} e_{\phi_{q}}^{2}$, by taking its time derivative $\dot{V}_{\phi_{q}}=e_{\phi_{q}} \dot{e}_{\phi_{q}}=$ 
$e_{\phi_{q}} e_{p_{q}}-\delta_{\phi_{q}} e_{\phi_{q}}^{2}, \delta_{\phi_{q}}>0$, where $e_{p_{q}}=p-p_{d}$ (velocity error). To satisfy this condition, a virtual control $p_{d}=\dot{\phi}_{q_{d}}-\delta_{\phi_{q}} e_{\phi_{q}}$ is chosen such that:

$$
e_{p_{q}}=p-p_{d}=p-\dot{\phi}_{q_{d}}+\delta_{\phi_{q}} e_{\phi_{q}} .
$$

The next step is to enhance $V_{\phi_{q}}$ with a quadratic term in $e_{p_{q}}$. To obtain a positive definite function as $V_{p_{q}}=\frac{1}{2} e_{p_{q}}^{2}+V_{\phi_{q}}$, and after taking the first time derivative, we obtain:

$$
\dot{V}_{p_{q}}=e_{p_{q}}\left(\left(b_{1} r+b_{2} p\right) q+b_{3} L_{t}+b_{4} N_{t}-\ddot{\phi}_{d}+\delta_{\phi_{q}} \dot{e}_{\phi_{q}}\right)-\delta_{\phi_{q}} e_{\phi_{q}}^{2}+e_{\phi_{q}} e_{p_{q}} .
$$

Using (15), the control law for the roll subsystem is defined as:

$$
L_{t}=\frac{1}{b_{3}}\left(-e_{\phi_{q}}-\delta_{p_{q}} e_{p_{q}}+\ddot{\phi}_{d}-\delta_{\phi_{q}} \dot{e}_{\phi_{q}}-\left(b_{1} r-b_{2} p\right) q-b_{4} N_{t}\right),
$$

so that $\dot{V}_{p_{q}}=-\delta_{\phi_{q}} e_{\phi_{q}}^{2}-\delta_{p_{q}} e_{p_{q}}^{2}$, which guarantees an asymptotic stable system for the appropriately chosen $\delta_{\phi_{q}}, \delta_{p_{q}}>0$. Using the same calculation procedure, we can define control law for the pitch and yaw angle, as well as position:

$$
\begin{aligned}
M_{t} & =\frac{1}{b_{7}}\left(\ddot{\theta}_{d}-e_{\theta_{q}}-\delta_{q_{q}} e_{q_{q}}-\delta_{\theta_{q}} \dot{\theta}_{\theta_{q}}+b_{6}\left(p^{2}-r^{2}\right)-b_{5} p r\right), \\
N_{t} & =\frac{1}{b_{9}}\left(\ddot{\psi}_{d}-e_{\psi_{q}}-\delta_{r_{q}} e_{r_{q}}-\delta_{\psi_{q}} \dot{e}_{\psi_{q}}-\left(b_{8} p-b_{2} r\right) q-b_{4} L_{t}\right) .
\end{aligned}
$$

The biplane quadrotor attitude is controlled by the control laws given in (16)-(18).

\subsection{Transition Mode}

Biplane quadrotors can switch quadrotor mode to fixed-wing mode by performing transition maneuvers. The biplane quadrotor is commanded to rotate linearly $\approx 90$ about the pitch axis to perform the transition. When the aerodynamic forces are sufficient, the controller switches from the quadrotor mode to the level flight mode. The attitude and altitude are controlled in transition mode, but there is no control over the $x-y$ position. In this transition mode, biplane quadrotor dynamics are the same as the quadrotor mode dynamics with the aerodynamic forces and movements, so the control laws for the transition mode are given as:

$$
\begin{aligned}
T & =\frac{m}{c \phi c \theta}\left(g-\frac{F_{a z}}{m}-\gamma_{z_{q}} e_{z_{q q}}^{j_{z_{q}} / i_{z_{q}}}-\zeta_{z_{q}}^{\frac{j i_{z_{q}}-j_{z_{q}}}{i_{p}}}-\lambda_{z_{q}} S_{z_{q}}-k_{z_{q}} \operatorname{sign}\left(S_{z_{q}}\right)\right), \\
L_{t} & =\frac{1}{b_{3}}\left(-e_{\phi_{q}}-\delta_{p_{q}} e_{p_{q}}+\ddot{\phi}_{d}-\delta_{\phi_{q}} \dot{e}_{\phi_{q}}-\left(b_{1} r-b_{2} p\right) q-b_{4}\left(N_{t}+N_{a}\right)-b_{3} L_{a}\right), \\
M_{t} & =\frac{1}{b_{7}}\left(\ddot{\theta}_{d}-e_{\theta_{q}}-\delta_{q_{q}} e_{q_{q}}-\delta_{\theta_{q}} \dot{e}_{\theta_{q}}+b_{6}\left(p^{2}-r^{2}\right)-b_{5} p r-b_{7} M_{a}\right) \\
N_{t} & =\frac{1}{b_{9}}\left(\ddot{\psi}_{d}-e_{\psi_{q}}-\delta_{r_{q}} e_{r_{q}}-\delta_{\psi_{q}} \dot{e}_{\psi_{q}}-\left(b_{8} p-b_{2} r\right) q-b_{4}\left(L_{t}+L_{a}\right)-b_{9} N_{a}\right) .
\end{aligned}
$$

\subsection{Flight Mode}

The level flight mode dynamics of the biplane quadrotor are like the dynamics of conventional fixed-wing aircraft. Biplane dynamics (1) and (2) with variables defined for quadrotor frame and transformed for fixed-wing axis are given as:

$$
\left[\begin{array}{c}
v_{x} \\
v_{y} \\
v_{z}
\end{array}\right]_{W}=\left[\begin{array}{ccc}
0 & 0 & -1 \\
0 & 1 & 0 \\
1 & 0 & 0
\end{array}\right]\left[\begin{array}{l}
v_{x} \\
v_{y} \\
v_{z}
\end{array}\right]_{Q} .
$$


Using (1), (2), and (23), the level flight mode dynamics are given as:

$$
\begin{aligned}
\dot{x} & =(c \theta c \psi) u+(s \phi s \theta c \psi-c \phi s \psi) v+(c \phi s \theta c \psi+s \phi s \psi) w, \\
\dot{y} & =(c \theta s \psi) u+(s \phi s \theta s \psi+c \phi c \psi) v+(c \phi s \theta s \psi-s \phi c \psi) w, \\
\dot{z} & =-u s \theta+v s \phi c \theta+w c \phi c \theta, \\
\dot{u} & =F_{a x} / m-g s \theta+p v-q u+T / m, \\
\dot{v} & =F_{a y} / m+g c \theta s \phi+p w-r u, \\
\dot{w} & =F_{a z} / m+g c \theta c \phi+r v-q w, \\
\dot{p} & =-p q\left(b_{w 3}+b_{w 9}\right)-q r\left(b_{w 11}-b_{w 12}\right)-b_{w 13}\left(L_{a}+L_{t}\right)+b_{w 5}\left(N_{a}+N_{t}\right), \\
\dot{q} & =b_{w 8} r^{2}+b_{w 9} p^{2}+2 b_{w 10} p r+b_{w 7}\left(M_{t}+M_{a}\right), \\
\dot{r} & =p q\left(b_{w 1}+b_{w 2}\right)+q r\left(b_{w 3}-b_{w 4}\right)+b_{w 5}\left(L_{t}+L_{a}\right)-b_{w 6}\left(N_{t}+N_{a}\right),
\end{aligned}
$$

where, $t(\cdot)=\tan (\cdot), b_{w 1}=I_{x z}\left(I_{y}+I_{x z}\right) / B, b_{w 2}=I_{z}^{2} / B, b_{w 3}=I_{x z}\left(I_{x}+I_{y}\right) / B, b_{w 4}=$ $I_{x} I_{y} / B, b_{w 5}=I_{x z} / B, b_{w 6}=I_{z} / B, b_{w 7}=1 / I_{y}, b_{w 88}=I_{x} / I_{y}, b_{w 9}=I_{z} / I_{y}, b_{w 10}=I_{x z} / I_{y}$ $b_{w 11}=I_{x}^{2} / B, b_{w 12}=I_{x z}\left(I_{y}-I_{x z}\right) / B, b_{w 13}=I_{x} / B$, and $B=I_{x} I_{z}-I_{x z}^{2}$.

Figure 3 shows the block diagram of the controller design for the level flight mode of biplane quadrotor where the desired attitude $\left[\phi_{d} \theta_{d} \psi_{d}\right]$ is generated by using $\left[x_{d} y_{d} z_{d}\right]$ and the current position $[x y z]$ of the biplane quadrotor. The required thrust $(T)$ is generated by the velocity controller, and the moments $\left[L_{t} M_{t} N_{t}\right]$ the attitude controller generates. Generated thrust and moments are given to the propulsion system, generating desired signals $\left[\begin{array}{llll}U_{1} & U_{2} & U_{3} & U_{4}\end{array}\right]$ to the respective actuator of the biplane quadrotor. The roles of controller 1 and controller 2 for the BSC, ITSMC, and hybrid control method are the same as explained earlier.

Control laws for the desired thrust in the level flight mode are derived by using the same procedure as explained in the quadrotor mode, so using Equation (27), the required thrust is calculated as:

$$
T=m\left(g s \theta-p v+q u-\frac{F_{a x}}{m}-\gamma_{z_{f}} \dot{e}_{z_{f}}^{j_{z_{f}} / i_{z_{f}}}-\zeta^{\frac{j_{z_{f}}}{2 i_{z_{f}}-j_{z}}}-\lambda_{z_{f}} S_{z_{f}}-k_{z_{f}} \operatorname{sign}\left(S_{z_{f}}\right)\right) .
$$

The attitude of the biplane quadrotor in the fixed wing mode are controlled by the BSC, and control laws are defined using the same procedure as explain in the quadrotor mode, so control laws for the attitude are:

$$
\begin{aligned}
L_{t} & =\frac{1}{b_{w 13}}\left(e_{\phi_{f}}+\delta_{p_{f}} e_{p_{f}}+\delta_{\phi_{f}} \dot{e}_{\phi_{f}}-\ddot{\phi}_{d}-p q\left(b_{w 3}+b_{w 9}\right)+q r\left(b_{w 12}-b_{w 11}\right)\right. \\
& \left.+b_{w 5}\left(N_{a}+N_{t}\right)+L_{w 13} L_{a}\right), \\
M_{t} & =\frac{1}{b_{w 7}}\left(-e_{\theta_{f}}-\delta_{q_{f}} e_{q_{f}}-\delta_{\theta_{f}} \dot{\theta}_{\theta_{f}}+\ddot{\theta}_{d}-b_{w 8} r^{2}-b_{w 9} p^{2}-2 b_{w 10} p r-b_{w 7} M_{a}\right), \\
N_{t} & =\frac{1}{b_{w 6}}\left(e_{\psi_{f}}+\delta_{r_{f}} e_{r_{f}}+\delta_{\psi_{f}} \dot{e}_{\psi_{f}}-\ddot{\psi}_{d}+p q\left(b_{w 1}+b_{w 2}\right)+q r\left(b_{w 3}-b_{w 4}\right)\right. \\
& \left.+b_{w 5}\left(L_{t}+L_{a}\right)+b_{w 6} N_{a}\right) .
\end{aligned}
$$

Here, the $y$ position and altitude are controlled by the desired pitch $\left(\psi_{d}\right)$ and yaw $\left(\theta_{d}\right)$ [40], which are given by using Equations (24) and (25) as:

$$
\begin{aligned}
& \theta_{d}=\sin ^{-1}\left(\frac{\dot{z}_{d}-k_{z}\left(z-z_{d}\right)}{\sqrt{a^{2}+b^{2}}}\right)+\tan ^{-1}\left(\frac{u}{v s \phi+w c \phi}\right), \\
& \psi_{d}=\tan ^{-1}\left(\frac{\dot{y}_{d}-k_{y}\left(y_{d}-y\right)}{\dot{x}_{d}+k_{x}\left(x_{d}-x\right)}\right),
\end{aligned}
$$


where $z_{d}$ is desired altitude, $x_{d}$ and $y_{d}$ are desired $x$ and $y$ positions, and $k_{x}, k_{y}, k_{\phi}$ and $k_{z}$ are tunable gains. We consider the roll angle as a linear function of the yaw angle, given as:

$$
\phi_{d}=k_{\phi}\left(\psi-\psi_{d}\right)
$$

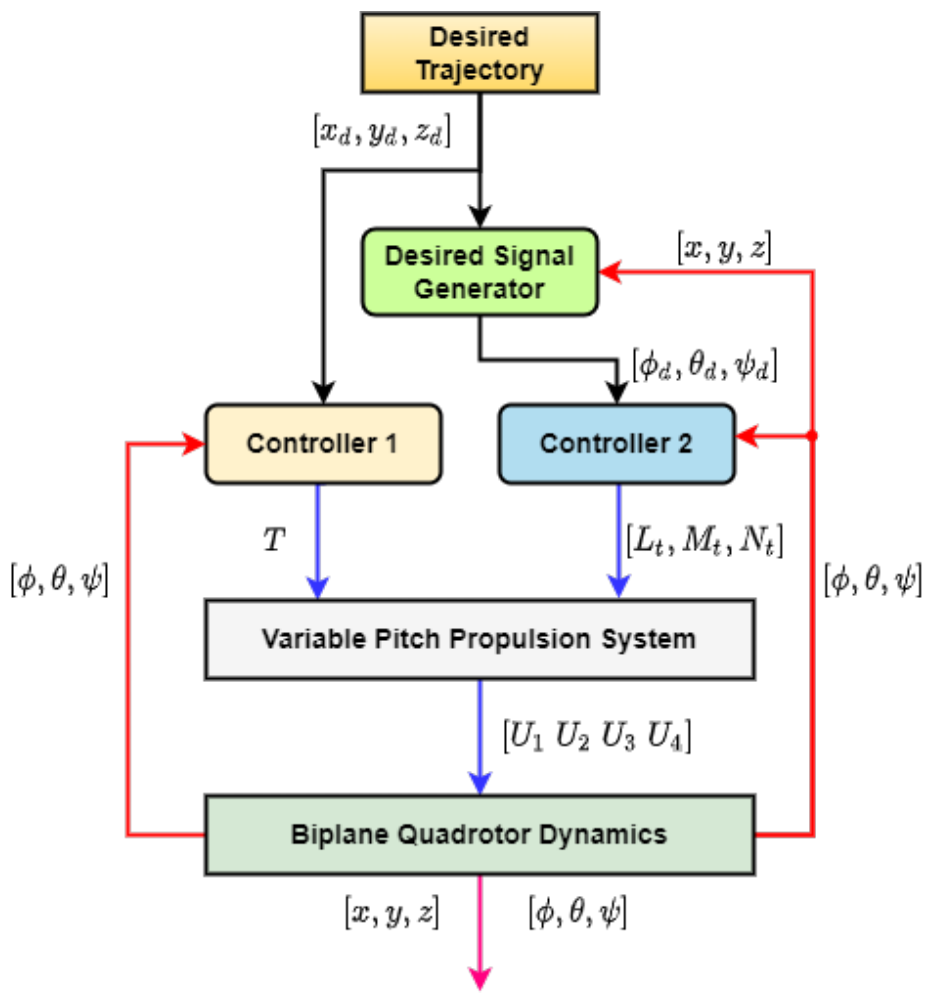

Figure 3. Block Diagram of controller design for Fixed wing mode.

\section{Results and Discussions}

In the last section, we designed a hybrid controller for the biplane quadrotor to track a desired trajectory. Simulation is carried out by using MATLAB Simulink for an initial position of the biplane quadrotor as $\left[\begin{array}{lll}x & y & z\end{array}\right]=\left[\begin{array}{lll}0.5 & 5 & 0\end{array}\right]$ and attitude as $[\phi \theta \psi]=\left[\begin{array}{lll}0 & 0 & 0\end{array}\right]$. The biplane specifications are given in Table 1.

Table 1. Biplane quadrotor parameters.

\begin{tabular}{cccc}
\hline Parameters & Value & Parameters & Value \\
\hline$g$ & $9.8 \mathrm{~m} \mathrm{~s}^{-2}$ & Wing area (single) & $0.754 \mathrm{~m}^{2}$ \\
Mass $(m)$ & $12 \mathrm{~kg}$ & Aspect ratio & 6.9 \\
$I_{x x}$ & $1.86 \mathrm{~kg} \cdot \mathrm{m}^{2}$ & Wing Span & $2.29 \mathrm{~m}$ \\
$I_{y y}$ & $2.03 \mathrm{~kg} \cdot \mathrm{m}^{2}$ & Gap-to-chord ratio & 2.56 \\
$I_{z z}$ & $3.617 \mathrm{~kg} \cdot \mathrm{m}^{2}$ & Slung load mass $\left(m_{l}\right)$ & $2 \mathrm{~kg}$ \\
\hline
\end{tabular}

BSC gains are shown in Table 2, ITSMC gains in Table 3, and hybrid controller gains are shown in Table 4 . 
Table 2. Backstepping Controller gains.

Quadrotor, Transition Mode

Fixed Wing Mode

\begin{tabular}{cccccccc}
\hline Parameter & Values & Parameter & Values & Parameter & Values & Parameter & Values \\
\hline$k_{x_{q}}$ & 1.5 & $k_{u_{q}}$ & 2.8 & $k_{x_{f}}$ & 15 & $k_{u_{f}}$ & 5 \\
\hline$k_{y_{q}}$ & 1.5 & $k_{v_{q}}$ & 2.8 & $k_{\phi_{f}}$ & 113 & $k_{p_{f}}$ & 13 \\
\hline$k_{z_{q}}$ & 3 & $k_{w_{q}}$ & 5 & $k_{\theta_{f}}$ & 113 & $k_{q_{f}}$ & 13 \\
\hline$k_{\phi_{q}}$ & 15 & $k_{p_{q}}$ & 18 & $k_{\psi_{f}}$ & 113 & $k_{r_{f}}$ & 13 \\
\hline$k_{\theta_{q}}$ & 15 & $k_{q_{q}}$ & 18 & & & & \\
\hline$k_{\psi_{q}}$ & 15 & $k_{r_{q}}$ & 18 & & & & \\
\hline
\end{tabular}

Table 3. ITSMC Controller Gains.

\begin{tabular}{|c|c|c|c|c|c|c|c|}
\hline \multicolumn{4}{|c|}{ Quadrotor, Transition Mode } & \multicolumn{4}{|c|}{ Fixed Wing Mode } \\
\hline Parameter & Values & Parameter & Values & Parameter & Values & Parameter & Values \\
\hline$\gamma_{x_{q}}$ & 2.70 & $\zeta_{x_{q}}$ & 0.317 & $\gamma_{x_{f}}$ & 1.27 & $\zeta_{x_{f}}$ & 3.57 \\
\hline$\gamma_{y_{q}}$ & 2.70 & $\zeta_{y_{q}}$ & 0.317 & $\gamma_{\phi_{f}}$ & 2.78 & $\zeta_{\phi_{f}}$ & 2.57 \\
\hline$\gamma_{z_{q}}$ & 2.70 & $\zeta_{z_{q}}$ & 1.57 & $\gamma_{\theta_{f}}$ & 2.78 & $\overline{\zeta_{\theta_{f}}}$ & 2.75 \\
\hline$\gamma_{\phi_{q}}$ & 1.78 & $\zeta_{\phi_{q}}$ & 1.57 & $\gamma_{\psi_{f}}$ & 2.78 & $\zeta_{\psi_{f}}$ & 2.57 \\
\hline$\gamma_{\theta_{q}}$ & 1.78 & $\zeta_{\theta_{q}}$ & 1.57 & $\lambda_{x_{f}}$ & 2.3 & $k_{x_{f}}$ & 1.66 \\
\hline$\gamma_{\psi_{q}}$ & 1.78 & $\zeta_{\psi_{q}}$ & 1.27 & $\lambda_{\phi_{f}}$ & 2 & $k_{\phi_{f}}$ & 2.66 \\
\hline$\lambda_{x_{q}}$ & 3.3 & $k_{x_{q}}$ & 2.66 & $\lambda_{\theta_{f}}$ & 2 & $k_{\theta_{f}}$ & 2.66 \\
\hline$\lambda_{y_{q}}$ & 3.3 & $k_{y_{q}}$ & 2.66 & $\lambda_{\psi_{f}}$ & 2 & $k_{\psi_{f}}$ & 2.66 \\
\hline$\lambda_{z_{q}}$ & 3.3 & $k_{z_{q}}$ & 1.66 & $p_{\phi_{f}}$ & 7 & $q_{\phi_{f}}$ & 5 \\
\hline$\lambda_{\phi_{q}}$ & 3.3 & $k_{\phi_{q}}$ & 5.66 & $p_{\theta_{f}}$ & 7 & $q_{\theta_{f}}$ & 5 \\
\hline$\lambda_{\theta_{q}}$ & 3.3 & $k_{\theta_{q}}$ & 8.66 & $p_{\psi_{f}}$ & 7 & $q_{\psi_{f}}$ & 5 \\
\hline$\lambda_{\psi_{q}}$ & 3.3 & $k_{\psi_{q}}$ & 5.66 & & & & \\
\hline$p_{x_{q}}$ & 9 & $q_{x_{q}}$ & 5 & & & & \\
\hline$p_{y_{q}}$ & 9 & $q_{y_{q}}$ & 5 & & & & \\
\hline$p_{z_{q}}$ & 9 & $q_{z_{q}}$ & 7 & & & & \\
\hline$p_{\phi_{q}}$ & 7 & $q_{\phi_{q}}$ & 5 & & & & \\
\hline$p_{\theta_{q}}$ & 7 & $q_{\theta_{q}}$ & 5 & & & & \\
\hline$p_{\psi_{q}}$ & 7 & $q_{\psi_{q}}$ & 5 & & & & \\
\hline
\end{tabular}


Table 4. Hybrid Controller gains.

\begin{tabular}{cccccccc}
\hline \multicolumn{3}{c}{ Quadrotor, Transition Mode } & \multicolumn{5}{c}{ Fixed Wing Mode } \\
\hline Parameter & Values & Parameter & Values & Parameter & Values & Parameter & Values \\
\hline$\gamma_{x_{q}}$ & 5.70 & $\zeta_{x_{q}}$ & 2.317 & $\gamma_{x_{f}}$ & 1.27 & $\zeta_{x_{f}}$ & 3.57 \\
\hline$\gamma_{y_{q}}$ & 5.70 & $\zeta_{y_{q}}$ & 2.317 & $\lambda_{x_{f}}$ & 2.3 & $k_{x_{f}}$ & 1.66 \\
\hline$\gamma_{z_{q}}$ & 8.70 & $\zeta_{z_{q}}$ & 3.57 & $p_{x_{f}}$ & 9 & $q_{x_{f}}$ & 7 \\
\hline$\lambda_{x_{q}}$ & 5.3 & $k_{x_{q}}$ & 3.66 & $k_{\phi_{f}}$ & 113 & $k_{p_{f}}$ & 13 \\
\hline$\lambda_{y_{q}}$ & 5.3 & $k_{y_{q}}$ & 3.66 & $k_{\theta_{f}}$ & 113 & $k_{q_{f}}$ & 13 \\
\hline$\lambda_{z_{q}}$ & 5.3 & $k_{z_{q}}$ & 2.66 & $k_{\psi_{f}}$ & 113 & $k_{r_{f}}$ & 13 \\
\hline$p_{x_{q}}$ & 9 & $q_{x_{q}}$ & 5 & & & & \\
\hline$p_{y_{q}}$ & 9 & $q_{y_{q}}$ & 5 & & & & \\
\hline$p_{z_{q}}$ & 9 & $q_{z_{q}}$ & 7 & & & & \\
\hline
\end{tabular}

Simulation is carried out for $t=0-1000 \mathrm{~s}$. Figure 4 shows the timeline of simulation where at $t=0$ to $t=20 \mathrm{~s}$, the biplane takes off with $5 \mathrm{~m} / \mathrm{s}$ velocity while holding its $x-y$ position.

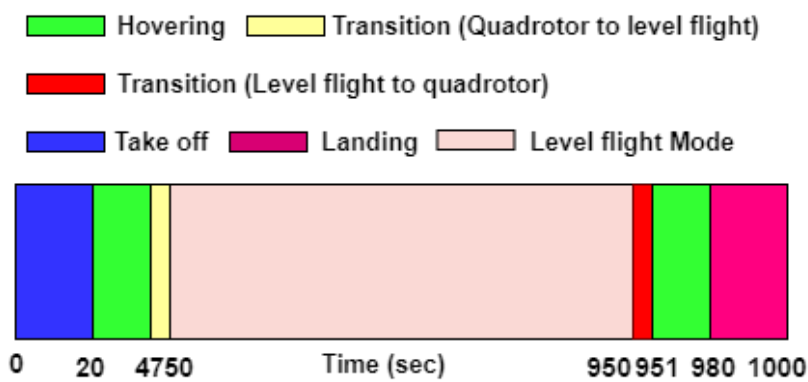

Figure 4. Timeline for simulation study.

After $t=20 \mathrm{~s}$, the UAV was commanded to hover for the next $27 \mathrm{~s}$, and after $t=47 \mathrm{~s}$, it will perform a transition maneuver for next $3 \mathrm{~s}$ and will switch into the fixed-wing UAV at $t=50 \mathrm{~s}$. For the next $900 \mathrm{~s}$, the biplane quadrotor will fly with different velocities and trajectories. At $t=50$ to $t=100 \mathrm{~s}$, it will fly with a $20 \mathrm{~m} / \mathrm{s}$ velocity in the $x$ direction and $3 \mathrm{~m} / \mathrm{s}$ velocity in the $y$ direction while holding its altitude at $100 \mathrm{~m}$. After $t=100$, for the next $800 \mathrm{~s}$, it will fly with a curvature trajectory where the velocity of the $x$ axis is $10 \mathrm{~m} / \mathrm{s}$ and the altitude is $100 \mathrm{~m}$. After, it will again increase its velocity to $20 \mathrm{~m} / \mathrm{s}$ in the $x$ direction and $3 \mathrm{~m} / \mathrm{s}$ in the $y$ direction. At $t=950 \mathrm{~s}$, it will perform a transition maneuver to switch from the fixed wing mode to the quadrotor mode. This transition period will be small for just $1 \mathrm{~s}$, and then it will hover again for $29 \mathrm{~s}$ and is commanded to land at $t=980 \mathrm{~s}$. In all the plots of the simulation results, the $x$-axis shows the simulation time, and the specific-state variable or parameters are shown in the $y$-axis.

Figure 5 shows the $x$ position tracking. After the transition from the quadrotor to level flight mode at $t=47$ to $50 \mathrm{~s}$, where we have no control over the $x-y$ position, the hybrid controller (ITSMC + BSC) response is faster at tracking the $x$ position again than the BSC and ITSMC controllers. At $t=100$, when the biplane quadrotor is commanded to suddenly change velocity from $20 \mathrm{~m} / \mathrm{s}$ to $10 \mathrm{~m} / \mathrm{s}$, as well as direction, the performance of the Hybrid controller generates less error and faster $x$ trajectory tracking than the ITSMC and BSC. 


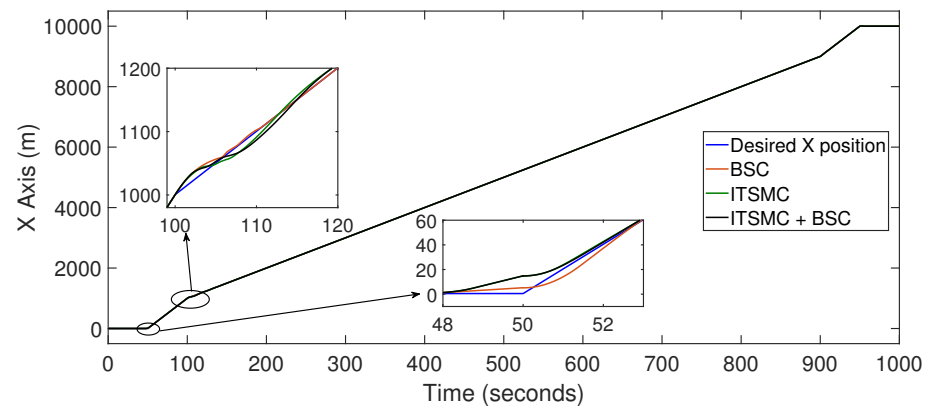

Figure 5. $X$ position tracking.

Figure 6 shows the $y$ axis position of the biplane quadrotor during the whole flight envelope. At $t=100$, when the direction and velocity are suddenly changed, the hybrid controller's performance is better than both the ITSMC and BSC.

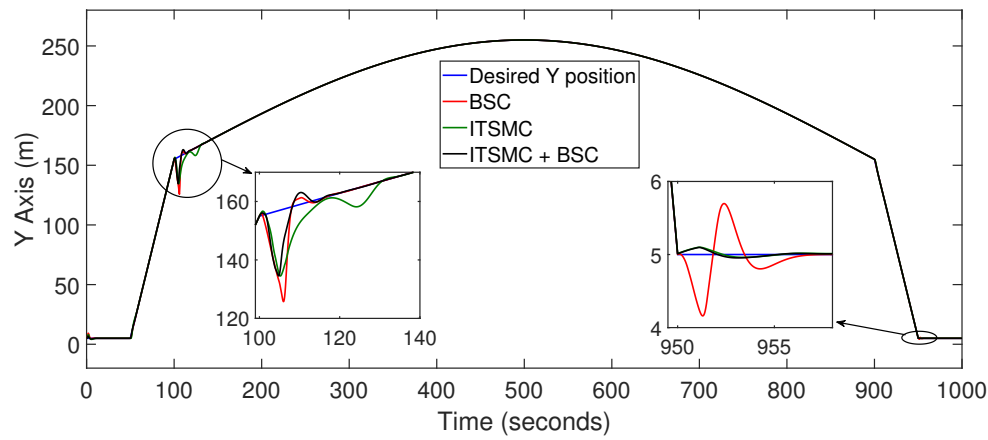

Figure 6. $Y$ position tracking.

It generates a lesser error than the BSC and has a lesser settling time than the ITSMC. At $t=950$, after performing the transition from the fixed-wing to the quadrotor flight, the BSC controller takes more time to provide a steady-state response than the ITSMC and the hybrid controller. The hybrid controller is slightly faster than the ITSMC during this time.

Figure 7 shows the altitude tracking performance of the controllers. At $t=20 \mathrm{~s}$, when the biplane quadrotor is commanded to hold its altitude after take-off, the controller's response is slightly faster than the BSC, while the ITSMC takes more time to hold the desired altitude. At $t=100 \mathrm{~s}$, with a sudden change in direction and speed of the biplane quadrotor, it is commanded to hold a constant altitude. The BSC generates a $6 \mathrm{~m}$ error in the altitude during this period, while the ITSMC generates less than a $2 \mathrm{~m}$ error. Although the hybrid controller generates a somewhat larger error than $2 \mathrm{~m}$, the settling time of the hybrid controller is less than the ITSMC. Finally, at $t=980 \mathrm{~s}$, the biplane quadrotor is commanded to land, and around this time, the hybrid controller is a little bit faster than the BSC but similar to the ITSMC.

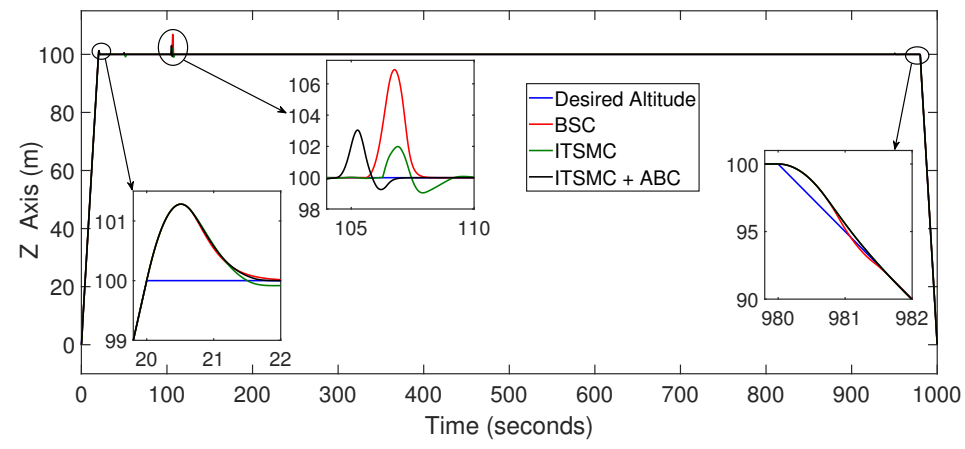

Figure 7. Altitude tracking. 
Figure 8 shows the roll angle tracking by controllers during the mission. During the transition phase at $t=47$ to $t=50 \mathrm{~s}$, all 3 controllers can track the desired roll angle, but after the transition, in fixed-wing mode, the ITSMC response is sluggish compared to the BSC and hybrid controller. During the second transition at $t=900 \mathrm{~s}$ to $901 \mathrm{~s}$, the change in the velocity and the direction of the biplane quadrotor, the ITSMC's response is slower than the BSC and hybrid controller.

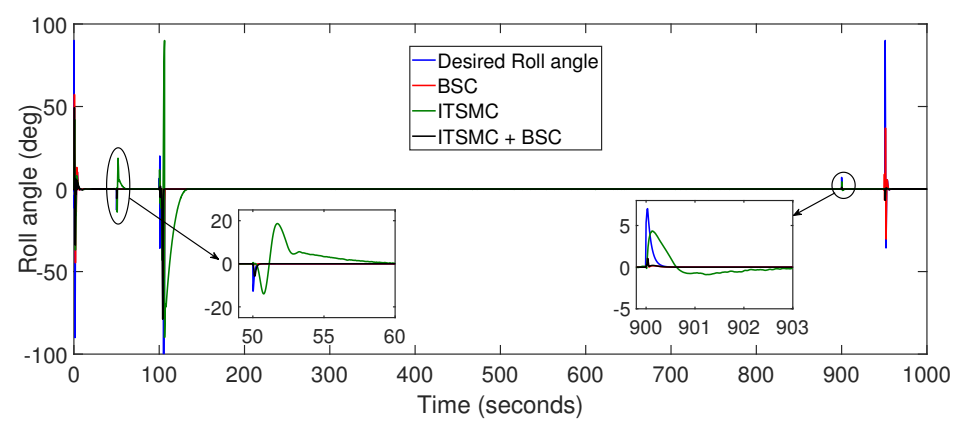

Figure 8. Roll angle tracking.

Figure 9 shows pitch angle tracking performance. All three controllers track pitch angle while decreasing linearly in the transition period $t=47-50$. Just after transition, in level flight mode, the response of the ITSMC is sluggish compared to the BSC and the hybrid controllers, and the BSC and the hybrid controller responses are the same because the attitude controller is the same in these controllers. At $t=951 \mathrm{~s}$ after performing the transition from fixed-wing mode to quadrotor mode, the performance of the BSC controller is better than the ITSMC and hybrid controllers.

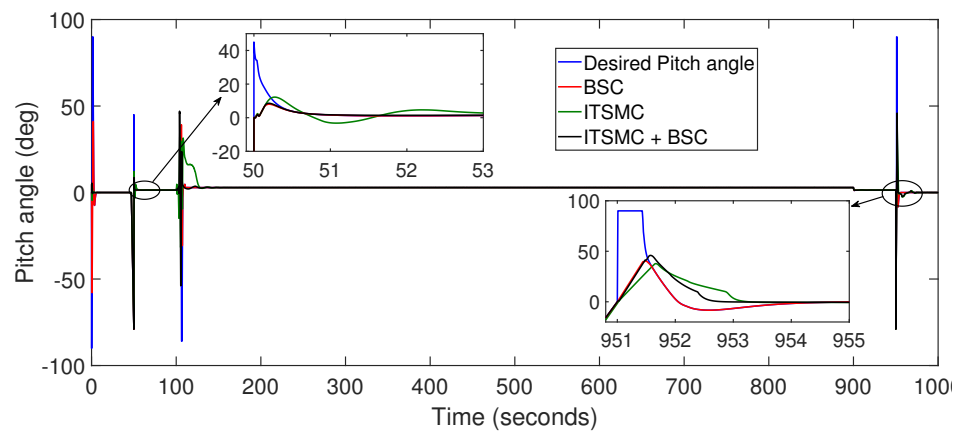

Figure 9. Pitch angle tracking.

Figure 10 shows the yaw angle tracking performance. In transition mode $(t=47-50 \mathrm{~s})$, all three controllers track the desired yaw angle, but after transition, in fixed-wing mode, the ITSMC response is sluggish compared to the BSC and hybrid controller. However, during the second change in velocity and direction of the biplane quadrotor (at $t=900-901 \mathrm{~s}$ ), the performance of the hybrid controller is better than the BSC and ITSMC.

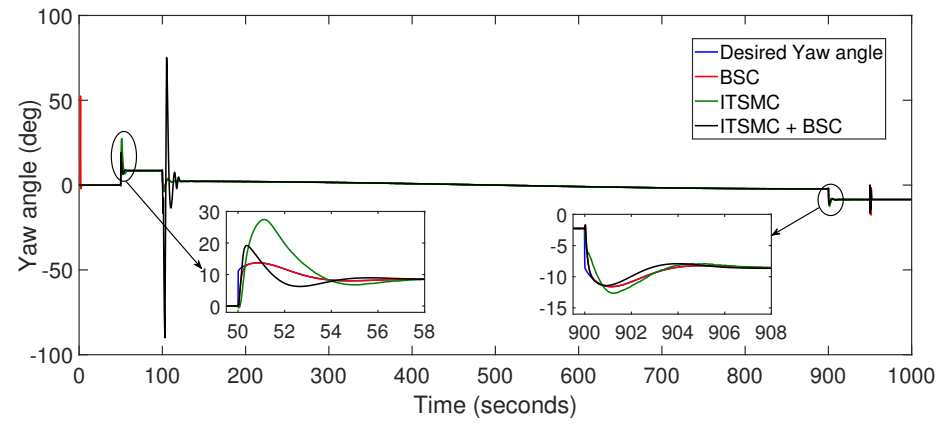

Figure 10. Yaw angle tracking. 
Figure 11 shows the velocity profile during the mission. The hybrid controller and ITSMC controller responses are the same because in the hybrid controller, the ITSMC also controls the position subsystem of the biplane quadrotor.

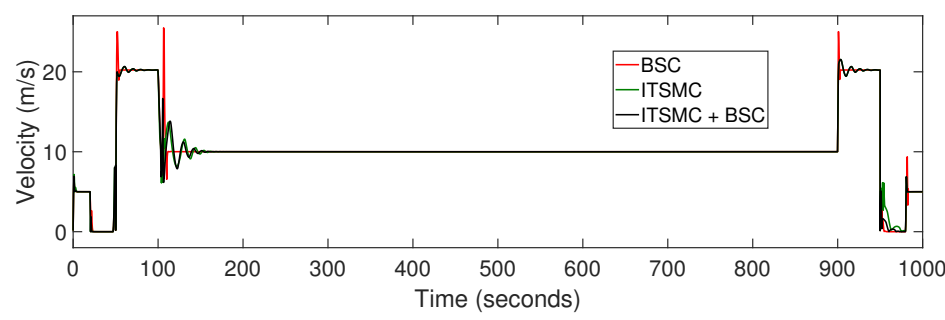

Figure 11. Velocity profile.

Figures 12 and 13 show the position tracking of the biplane quadrotor during the change in the mass. As observed, there is no visible change in the $x-y$ position of the biplane quadrotor with mass change at $t=50 \mathrm{~s}$. However, in the altitude, BSC generates a steady-state error of around $20 \mathrm{~cm}$ after mass changes from $18 \mathrm{~kg}$ to $12 \mathrm{~kg}$. In contrast, the ITMSC and hybrid controllers can track altitude again, but the hybrid controllers have generated lesser errors faster than the ITSMC.
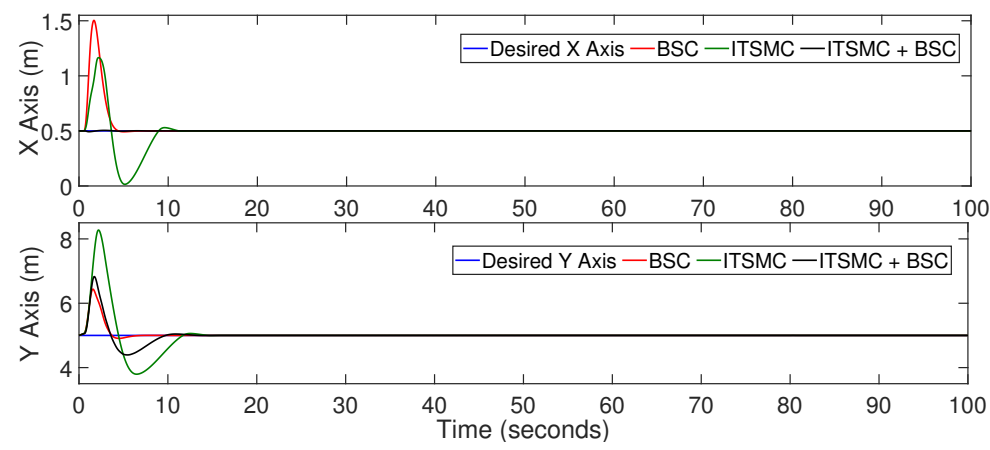

Figure 12. The $x-y$ position tracking during the mass change.

In this hybrid controller, the ITSMC, which is more robust, controls the position subsystem, and the BSC controls the attitude subsystem providing a fast response. So, the hybrid controller incorporates the advantages of both the control method as validated by the simulation results and the performance index shown in Table 5.

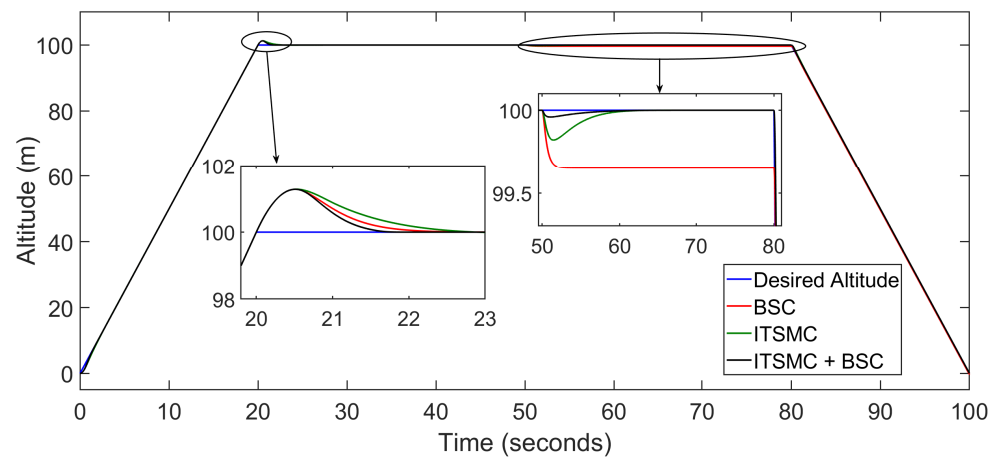

Figure 13. Altitude tracking during the mass change. 
Table 5. Integral Time Absolute Error (ITAE) with (i) trajectory tracking and (ii) mass change.

\begin{tabular}{ccccc}
\hline Sr.No & Time (s) & BSC & ITSMC & ITSMC + BSC \\
\hline \multirow{2}{*}{ (i) } & $0-50$ & 390 & 395 & 382 \\
& $50-950$ & $1.57 \times 10^{4}$ & $1.56 \times 10^{4}$ & $1.52 \times 10^{4}$ \\
& $950-1000$ & 132 & 128 & 122 \\
\hline (ii) & $0-100$ & 1305 & 230 & 133 \\
\hline
\end{tabular}

Figure 14 shows three-dimension trajectory tracking performance by all three controllers. The overall hybrid controller performance is better than the BSC and ITSMC.

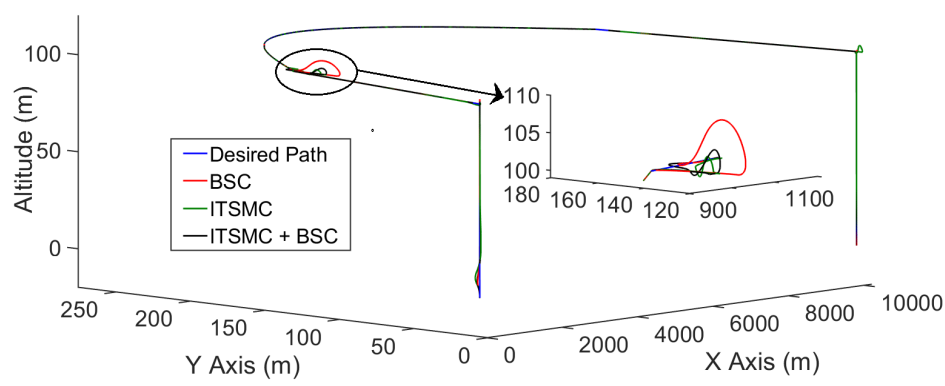

Figure 14. Three-dimensional trajectory tracking.

If the ITSMC controls the attitude in the hybrid controller and the BSC-based controller controls the position, then there is a steady-state error in the altitude during mass change. Altitude tracking has the highest impact due to the mass change while the biplane quadrotor is in the hover state, and ITSMC provides a robust response compared to the BSC.

\section{Conclusions}

A biplane quadrotor is a hybrid UAV that can take off, hover, and land like a rotarywing quadrotor and fly with high velocity like a fixed-wing quadrotor. This simulation study, carried out using MATLAB Simulink, proposed a hybrid controller (ITSMC + BSC) for a biplane quadrotor to track the desired trajectory and compared its performance with ITSMC- and BSC-based controllers. The outcomes of this study are as follows:

- In the $x$-axis trajectory tracking, just after transition mode at $t=50 \mathrm{~s}$, the hybrid controller takes less time and generates lesser error than the BSC. At $t=100 \mathrm{~s}$, the biplane quadrotor commanded to suddenly change velocity from $20 \mathrm{~m} / \mathrm{s}$ to $10 \mathrm{~m} / \mathrm{s}$ results in superior performance in the hybrid controller than the ITSMC and BSC.

- At $t=100 \mathrm{~s}$, the ITSMC takes longer to track in the y-axis trajectory, and the BSC generates the most significant error among these controllers. However, the hybrid controller can track within a $15 \mathrm{~m}$ error in the desired trajectory and takes $17 \mathrm{~s}$.

- The hybrid controller effectively manages altitude tracking of the biplane quadrotor. At $t=20 \mathrm{~s}$, when commanded to hover after take off at $5 \mathrm{~m} / \mathrm{s}$ velocity, the performance of the ITSMC is sluggish, taking more than $3 \mathrm{~s}$ to hold the altitude. In comparison, the hybrid controller is faster than the ITSMC, and BSC and takes only $2 \mathrm{~s}$ to track the altitude. When a sudden mass change happens at $t=100 \mathrm{~s}$, the hybrid controller generates $2 \mathrm{~m}$ error and takes only $3 \mathrm{~s}$ to track the altitude again, while the BSC generates a significant error, and ITSMC takes more time.

- In attitude tracking, the response of ITSMC is slower than BSC and hybrid controllers.

- The performance of these controllers is also evaluated in the scenarios when a sudden mass change happens. Again, the hybrid controller's performance is far superior to the other two controllers as the BSC generates $20 \mathrm{~cm}$ steady-state error while the ITSMC has a slow response.

- Although the change in the parameters is not accurately measured analytically, for instance, using an adaptive backstepping controller, the robustness of the proposed 
control methods adopted is still proven numerically through simulations, as shown in Figure 13.

- $\quad$ The BSC and ITSMC controllers track the desired trajectory, but a hybrid controller is an obvious choice when we require faster and more precise control.

\section{Future Work}

A simulation study in MATLAB Simulink successfully validates the proposed hybrid controller. The next step is implementing such a controller in Gazebo, a 3-Dimension Simulator, helping to identify the effectiveness of the controller in the 3D space in the presence of the different disturbances and different scenarios. The last step is to implement it to the actual hardware using the PX4 flight controller.

Author Contributions: Conceptualization, N.D. and D.D.; methodology, N.D., D.D. and J.J.R.; software, N.D. and D.D.; validation, N.D. and D.D.; formal analysis, N.D. and D.D.; writing- original draft preparation, N.D., D.D. and J.J.R.; writing—review and editing, N.D., D.D. and J.J.R.; supervision, D.D.; funding acquisition, D.D. and J.J.R. All authors have read and agreed to the published version of the manuscript.

Funding: This research received no external funding.

Institutional Review Board Statement: Not applicable.

Informed Consent Statement: Not applicable.

Data Availability Statement: Not applicable.

Conflicts of Interest: The authors declare no conflict of interest.

\section{References}

1. Suzuki, S.; Zhijia, R.; Horita, Y.; Nonami, K.; Kimura, G.; Bando, T.; Hirabayashi, D.; Furuya, M.; Yasuda, K. Attitude control of quad rotors QTW-UAV with tilt wing mechanism. J. Syst. Des. Dyn. 2010, 4, 416-428. [CrossRef]

2. Stone, R.H.; Anderson, P.; Hutchison, C.; Tsai, A.; Gibbens, P.; Wong, K.C. Flight Testing of the T-Wing Tail-Sitter Unmanned Air Vehicle. J. Aircr. 2008, 45, 673-685. [CrossRef]

3. Ko, A.; Ohanian, O.; Gelhausen, P. Ducted Fan UAV Modeling and Simulation in Preliminary Design. In Proceedings of the AIAA Modeling and Simulation Technologies Conference and Exhibit, Hilton Head, SC, USA, 20-23 August 2007. [CrossRef]

4. Swarnkar, S.; Parwana, H.; Kothari, M.; Abhishek, A. Biplane-quadrotor tail-sitter uav: Flight dynamics and control. J. Guid. Control Dyn. 2018, 41, 1049-1067. [CrossRef]

5. Hrishikeshavan, V.; Bogdanowicz, C.; Chopra, I. Design, Performance and Testing of a Quad Rotor Biplane Micro Air Vehicle for Multi Role Missions. Int. J. Micro Air Veh. 2014, 6, 155-173. [CrossRef]

6. Ryseck, P.; Yeo, D.W.; Hrishikeshavan, V.; Chopra, I. Expanding the Mission Capabilities of a Quadrotor Biplane Tail-sitter with Morphing Winglets. In Proceedings of the AIAA Scitech 2020 Forum, Orlando, FL, USA, 6-10 January 2020. [CrossRef]

7. Reddinger, J.P.F.; McIntosh, K.; Zhao, D.; Mishra, S. Modeling and Trajectory Control of a Transitioning Quadrotor Biplane Tailsitter. In Proceedings of the Vertical Flight Society 75th Annual Forum, Philadelphia, PA, USA, 13-16 May 2019.

8. Yeo, D.; Hrishikeshavan, V.; Chopra, I. Gust Detection and Mitigation on a Quad Rotor Biplane. In Proceedings of the AIAA Atmospheric Flight Mechanics Conference, San Diego, CA, USA, 4-8 January 2016. [CrossRef]

9. Raj, N.; Simha, A.; Kothari, M.; Abhishek.; Banavar, R.N. Iterative Learning based feedforward control for Transition of a Biplane-Quadrotor Tailsitter UAS. In Proceedings of the 2020 IEEE International Conference on Robotics and Automation (ICRA), Paris, France, 31 May-31 August 2020; pp. 321-327. [CrossRef]

10. Phillips, B.; Hrishikeshavan, V.; Rand, O.; Chopra, I. Design and Development of a Scaled Quadrotor Biplane with Variable Pitch Proprotors for Rapid Payload Delivery. In Proceedings of the American Helicopter Society 72nd Annual Forum, West Palm Beach, FL, USA, 16-19 May 2016.

11. Sandiwan, A.P.; Cahyadi, A.; Herdjunanto, S. Robust proportional-derivative control on $\mathrm{SO}(3)$ with disturbance compensation for quadrotor UAV. Int. J. Control Autom. Syst. 2017, 15, 2329-2342. [CrossRef]

12. Bouabdallah, S.; Noth, A.; Siegwart, R. PID vs. LQ control techniques applied to an indoor micro quadrotor. In Proceedings of the IEEE/RSJ International Conference on Intelligent Robots and Systems (IROS) (IEEE Cat. No.04CH37566), Sendai, Japan, 28 September-2 October 2004; Volume 3, pp. 2451-2456. [CrossRef]

13. Zhong, J.; Song, B.; Li, Y.; Xuan, J. $L_{1}$ Adaptive Control of a Dual-Rotor Tail-Sitter Unmanned Aerial Vehicle with Input Constraints During Hover Flight. IEEE Access 2019, 7, 51312-51328. [CrossRef]

14. Liu, H.; Peng, F.; Lewis, F.L.; Wan, Y. Robust Tracking Control for Tail-Sitters in Flight Mode Transitions. IEEE Trans. Aerosp. Electron. Syst. 2019, 55, 2023-2035. [CrossRef] 
15. Zhang, S.; Fei, Q.; Liang, J.; Geng, Q. Modeling and control for longitudinal attitude of a twin-rotor tail-sitter unmanned aerial vehicle. In Proceedings of the 13th IEEE International Conference on Control Automation (ICCA), Ohrid, North Macedonia, 3-6 July 2017; pp. 816-821. [CrossRef]

16. Xi, L.; Zhu, Q.; Zhang, D. Sliding mode control design based on fuzzy reaching law for yaw angle of a Tail-sitter UAV. In Proceedings of the 2016 22nd International Conference on Automation and Computing (ICAC), Colchester, UK, 7-8 September 2016; pp. 238-243. [CrossRef]

17. Zhang, M.; Liu, H.H. Tracking a Moving Target by a Fixed-wing UAV Based on Sliding Mode Control. In Proceedings of the AIAA Guidance, Navigation, and Control (GNC) Conference, Boston, MA, USA 19-22 August 2013. [CrossRef]

18. Gambhire, S.J.; Kishore, D.R.; Londhe, P.S.; Pawar, S.N. Review of sliding mode based control techniques for control system applications. Int. J. Dyn. Control 2020, 9, 363-378. [CrossRef]

19. Dalwadi, N.; Deb, D.; Kothari, M.; Ozana, S. Disturbance Observer-Based Backstepping Control of Tail-Sitter UAVs. Actuators 2021, 10, 119. [CrossRef]

20. Lyu, X.; Zhou, J.; Gu, H.; Li, Z.; Shen, S.; Zhang, F. Disturbance Observer Based Hovering Control of Quadrotor Tail-Sitter VTOL UAVs Using $H_{\infty}$ Synthesis. IEEE Robot. Autom. Lett. 2018, 3, 2910-2917. [CrossRef]

21. Abdul Salam, A.; Ibraheem, I. Nonlinear PID controller design for a 6-DOF UAV quadrotor system. Eng. Sci. Technol. Int. J. 2019, 22, 1087-1097. [CrossRef]

22. Moreno-Valenzuela, J.; Pérez-Alcocer, R.; Guerrero-Medina, M.; Dzul, A. Nonlinear PID-Type Controller for Quadrotor Trajectory Tracking. IEEE/ASME Trans. Mechatron. 2018, 23, 2436-2447. [CrossRef]

23. Zhang, D.; Chen, Z.; Xi, L. Adaptive dual fuzzy PID control method for longitudinal attitude control of tail-sitter UAV In Proceedings of the 2016 22nd International Conference on Automation and Computing (ICAC), Colchester, UK, 7-8 September 2016; pp. 378-382. [CrossRef]

24. Jung, Y.; Shim, D.H. Development and Application of Controller for Transition Flight of Tail-Sitter UAV. J. Intell. Robot. Syst. 2011, 65, 137-152. [CrossRef]

25. Demirhan, M.; Premachandra, C. Development of an Automated Camera-Based Drone Landing System. IEEE Access 2020, 8, 202111-202121. [CrossRef]

26. Shehzad, M.F.; Bilal, A.; Ahmad, H. Position \& Attitude Control of an Aerial Robot (Quadrotor) with Intelligent PID and State feedback LQR Controller: A Comparative Approach. In Proceedings of the 2019 16th International Bhurban Conference on Applied Sciences and Technology (IBCAST), Islamabad, Pakistan, 8-12 January 2019; pp. 340-346. [CrossRef]

27. Khodja, M.A.; Tadjine, M.; Boucherit, M.S.; Benzaoui, M. Tuning PID attitude stabilization of a quadrotor using particle swarm optimization (experimental). Int. J. Simul. Multidiscip. Des. Optim. 2017, 8, A8. [CrossRef]

28. Selamat, N.A.; Daud, F.S.; Jaafar, H.I.; Shamsudin, N.H. Comparison of LQR and PID controller tuning using PSO for Coupled Tank System. In Proceedings of the 2015 IEEE 11th International Colloquium on Signal Processing Its Applications (CSPA), Kuala Lumpur, Malaysia, 6-8 March 2015; pp. 46-51. [CrossRef]

29. Khatoon, S.; Nasiruddin, I.; Shahid, M. Design and Simulation of a Hybrid PD-ANFIS Controller for Attitude Tracking Control of a Quadrotor UAV. Arab. J. Sci. Eng. 2017, 42, 5211-5229. [CrossRef]

30. Raza, S.A.; Etele, J.; Fusina, G. Hybrid Controller for Improved Position Control of Quadrotors in Urban Wind Conditions. J. Aircr. 2018, 55, 1014-1023. [CrossRef]

31. Dalwadi, N.; Deb, D.; Muyeen, S.M. Adaptive backstepping controller design of quadrotor biplane for payload delivery. IET Intell. Transp. Syst. 2022. [CrossRef]

32. Morshed, M.J.; Fekih, A. Design of a chattering-free integral terminal sliding mode approach for DFIG-based wind energy systems. Optim. Control Appl. Methods 2020, 41, 1718-1734. [CrossRef]

33. Su, Y.; Zheng, C. A new nonsingular integral terminal sliding mode control for robot manipulators. Int. J. Syst. Sci. 2020, 51, 1418-1428. [CrossRef]

34. Ullah, S.; Khan, Q.; Mehmood, A.; Kirmani, S.A.M.; Mechali, O. Neuro-adaptive fast integral terminal sliding mode control design with variable gain robust exact differentiator for under-actuated quadcopter UAV. ISA Trans. 2021, 120, 293-304. [CrossRef]

35. Labbadi, M.; Cherkaoui, M. Robust Integral Terminal Sliding Mode Control for Quadrotor UAV with External Disturbances. Int. J. Aerosp. Eng. 2019, 2019, 2016416. [CrossRef]

36. Labbadi, M.; Cherkaoui, M. Adaptive Fractional-Order Nonsingular Fast Terminal Sliding Mode Based Robust Tracking Control of Quadrotor UAV With Gaussian Random Disturbances and Uncertainties. IEEE Trans. Aerosp. Electron. Syst. 2021, 57, 2265-2277. [CrossRef]

37. Mofid, O.; Mobayen, S.; Wong, W.K. Adaptive Terminal Sliding Mode Control for Attitude and Position Tracking Control of Quadrotor UAVs in the Existence of External Disturbance. IEEE Access 2021, 9, 3428-3440. [CrossRef]

38. Modirrousta, A.; Khodabandeh, M. A novel nonlinear hybrid controller design for an uncertain quadrotor with disturbances. Aerosp. Sci. Technol. 2015, 45, 294-308. [CrossRef]

39. Huang, S.; Huang, J.; Cai, Z.; Cui, H. Adaptive Backstepping Sliding Mode Control for Quadrotor UAV. Sci. Program. 2021, 2021, 3997648. [CrossRef]

40. Ambati, P.R.; Padhi, R. A Neuro-Adaptive Augmented Dynamic Inversion Design for Robust Auto-Landing. IFAC Proc. Vol. 2014, 47, 12202-12207. [CrossRef] 